\title{
Aortic Involvement in Antineutrophil Cytoplasmic Antibodies Vasculitis, a Coincidence or a Real Association?
}

\author{
Ezza Tariq ${ }^{1,2}$, Katukuri Nishanth ${ }^{3}$, Assam Arshid ${ }^{4}$, Mohammed Miqdad ${ }^{5}$, Ivan Cancarevic 3 \\ 1. Medicine, California Institute of Behavioral Neurosciences \& Psychology, Fairfield, USA 2. Medicine, Nishtar \\ Medical College, Multan, PAK 3. Internal Medicine, California Institute of Behavioral Neurosciences \& Psychology, \\ Fairfield, USA 4. Surgery, California Institute of Behavioral Neurosciences \& Psychology, Fairfield, USA 5. Internal \\ Medicine, California Institute of Behavioral Neurosciences \& Psychology, Fairfield, SAU
}

Corresponding author: Ezza Tariq, ezzatariq.et@gmail.com

\begin{abstract}
Antineutrophil cytoplasmic antibodies (ANCA)-associated vasculitis (AAV) is a type of small-vessel vasculitis. It is unusual for ANCA to involve aorta. However, multiple cases have been found where ANCA involved large vessels, particularly the aorta. Among vasculitides, aortic vasculitis is a part of Takayasu arteritis (TAK). In this review article, we tried to find the mechanism behind the aortic involvement in AAV. PubMed was used as a primary search engine, and all the available cases of aortic, as well as large-vessel involvement in ANCA-associated vasculitis, were thoroughly reviewed. Very limited data was available that could provide the mechanism behind this involvement. It is observed that ANCA-associated aortitis is more common in immunocompromised people; however, cases in previously healthy individuals have also been found. Pathogenesis of ANCA-related aortitis is different from Takayasu arteritis and is more close to ANCA-associated small vasculitis. ANCA-related aortitis involves the aorta through the same mechanism as it uses to involve small vessels. This rare manifestation of ANCA-associated vasculitis could be lifethreatening but has a good prognosis if timely diagnosed and treated. ANCA-associated vasculitis must be considered as a differential diagnosis while treating a case of aortitis. We believe that there is a need to revise the classification of different types of vasculitides, and physicians should be aware of the possible overlap between different forms of vasculitides.
\end{abstract}

Received 06/27/2020

Review began $07 / 08 / 2020$ Review ended 07/24/2020 Published 08/12/2020

\section{(c) Copyright 2020}

Tariq et al. This is an open access article distributed under the terms of the Creative Commons Attribution License CC-BY 4.0., which permits unrestricted use, distribution, and reproduction in any medium, provided the original author and source are credited.
Categories: Internal Medicine, Allergy/Immunology, Rheumatology

Keywords: aortitis, anca vasculitis, vasculitides, granulomatosis with polyangiitis, large vessel vasculitis

\section{Introduction And Background}

Vasculitides is a group of disorders characterized by inflammation of vessels of various sizes [1]. This causes diminished blood flow, resulting in tissue damage and ultimately, necrosis [1]. Vasculitides nomenclature was defined in the International Chapel Hill Consensus Conference according to their vessel sizes and was divided into three main classes: large, medium, and small [2-3]. Large-vessel vasculitis is divided into Takayasu arteritis (TAK) and giant cell arteritis (GCA) [4]. Medium-vessel vasculitis involves polyarteritis nodosa and Kawasaki disease [2-3]. Small-vessel vasculitis is further divided into antineutrophil cytoplasmic antibodies (ANCA)-associated vasculitis (AAV), characterized by the lack or small number of immune deposits in the vessel wall, and immune complex small-vessel vasculitis [2]. ANCA-associated vasculitis includes microscopic polyangiitis (MPA), granulomatosis with polyangiitis (GPA), eosinophilic granulomatosis with polyangiitis, and AAV involving single organs (AAV limited to kidney) [2,5]. Among vasculitides, aortic involvement is predominantly present in Takayasu arteritis $[2,5]$.

GPA is a rare disease that was first described in 1930 [6]. It is a necrotizing vasculitis associated with cytoplasmic ANCA [7]. A limited form of granulomatosis with polyangiitis involves the upper respiratory tract, while a generalized form involves kidneys and/or lower respiratory tract [7]. MPA is associated with anti-myeloperoxidase antibodies and involves only the lower respiratory tract and kidney [8]. However, general features of inflammation such as fever, weight loss, peripheral neuropathy, or muscular and articular symptoms may also be present [8]. Granulomatosis with polyangiitis is characterized by granulomatous inflammation, while non-granulomatous inflammation, involving the upper and lower respiratory tract, is characteristic of MPA [5].

It is unusual for ANCA-associated vasculitis to cause aortic inflammation [1]. The way ANCA affects vessel walls is not clear; various factors such as infection, environmental factors, and genetic factors as well as certain drugs including hydralazine, propylthiouracil, minocycline, cocaine use, and alpha- 1 antitrypsin deficiency (AAT) are assumed to be the possible risk factors [9-11]. It is suggested that ANCA leads to aortitis by causing vasorum vasculitis in the adventitia, which later spreads to media and intima [12]. It is also proposed that retroperitoneal arteries involvement (periaortitis) ultimately leads to aortic inflammation [13-14]. However, there is also a possibility of an overlap between Takayasu arteritis and ANCA-associated vasculitis $[4,15]$. 
In this review article, we will discuss the pathophysiology of ANCA-associated vasculitis, especially granulomatosis with polyangiitis, and aortic involvement with it. We will also talk about the management of ANCA-related aortic involvement.

\section{Review}

\section{Method and results}

It is a narrative review article. PubMed was used as the primary search engine. To find articles with direct relevance, "ANCA" and "aortitis" MeSH keywords were used, which showed 18 articles in total. These were reduced to 12 after applying a 10-year filter. No filters related to age or sex were applied. No statistical analysis was done, and no quality assessment tools were applied. To discuss the topic further, we did extensive research on PubMed using terms "Takayasu arteritis in ANCA vasculitis," "Vasculitides," and "Aorta in granulomatosis with polyangiitis," which showed 132, 108842, and 142 articles, respectively. Articles containing at least one keyword and those published in peer-reviewed scientific journals were included, while rest were excluded. All the data were collected in an ethical manner, and all the efforts were taken to minimize plagiarism.

\section{Presentation of aortic diseases in AAV}

Aortic diseases proximal to ligamentum arteriosum are mostly non-atherosclerotic in nature, while those distal to it are mainly atherosclerotic [16]. ANCA-related aortic disease may present as an aneurysmal disease, aortic dissection, aortic rupture, aortic regurge, and even death [12]. Among AAV, aortic involvement is reported in both GPA and MPA but not in Churg-Strauss syndrome [12]. Patient presentation with constitutional symptoms may lead to misdiagnosis and, ultimately, serious outcomes in ANCA-related aortitis $[12,16]$. Chirinos et al. described a case of a 53-year-old woman who presented with fever, weight loss, malaise, night sweats, and recurrent pulmonary infiltrates and was diagnosed with communityacquired pneumonia [12]. It was later found that she had MPA, which led to aortic dissection and, ultimately, death [12]. Aortic involvement can manifest even before the typical features of ANCA-associated vasculitis or even in the absence of small-vessel vasculitis [13,17-20]. Sakemi et al. discussed a case of periaortic soft tissue mass extending from the thoracic aorta to bilateral common iliac arteries, in which no other findings related to ANCA-associated vasculitis were present, but the patient tested positive for p-ANCA [20]. Sieber et al. described a case of asymptomatic GPA, in which GPA was diagnosed nine months after granulomatous aortitis and aneurysm formation [17]. Carels et al. described a case of a 63-year-old man who developed GPA seven years later after having an aortic aneurysm, and at the time of GPA diagnosis, revision of the biopsy taken seven years ago showed typical necrotic granuloma of GPA in the aortic wall [13]. In another case described by Pan et al., a 28-year-old man, who initially presented with chest pain due to aortic dissection, was later diagnosed with GPA [18].

A possibility of aortic involvement should always be kept in mind while treating a patient with AAV as timely diagnosis and management could reduce the morbidity as well as mortality related to aortic involvement in ANCA-associated vasculitis [12].

\section{Risk factors leading to aortitis in AAV}

Risk factors leading to the pathogenesis of ANCA-related aortitis are not clear [9-11]. However, certain immunosuppressant drugs have been found as a possible risk factor [21-22]. Murakami et al. described a case of a 57-year-old man who was taking bevacizumab for lung adenocarcinoma and later developed p-ANCApositive periaortitis [21]. Ginsberg et al. mentioned etanercept, an anti-tumor necrosis factor, as a possible cause of ANCA-associated large-vessel vasculitis [22]. Voorzaat et al. described a fatal case of aortic dissection due to ANCA, in which the patient was tested positive for AAT [23].

Very limited data is available that can provide a strong association between possible risk factors and aortitis related to ANCA-associated vasculitis. After reviewing the available studies about ANCA-related aortitis, we suggest that there is a need for extensive research to explore the possible risk factors that are responsible not only for ANCA-associated vasculitis but also for aortic involvement in it.

\section{Pathophysiology}

Antineutrophil antibodies are found in the cytoplasmic granules of monocytes and neutrophils [24]. In small-vessel vasculitis, antibodies are formed against two types of antigens [24]. ANCA directed against anti-proteinase 3 is categorized into GPA, and those against anti-myeloperoxidase are associated with MPA [24-25]. It is proposed that antineutrophil cytoplasmic antibodies are produced against the newly exposed epitopes referred to as cryptic sites of the autoantigen, which later involves the rest of the molecule [26]. It then spreads by "epitope spreading" to involve other components of a macromolecular protein complex [26]. Another hypothesis suggests that it is the autoantigen's complementary protein that initiates the immunological process in AAV [27-28]. Since vasculitis is an antigen-related process, its pathogenesis should be T-cell dependent [28]. T cells then overproduce TNF-alpha and interferon-gamma, which are major cytokines in the GPA-related inflammatory process [28]. However, neutrophil activation, monocytes, and Bcells also play an important role [29-31]. Schildhaus et al. suggested that the mechanism through which 
ANCA involves large vessels is the same as for ANCA-associated small-vessel vasculitis [16]. He also proposed that ANCA involves large vessels by inflammation of intima without affecting media and adventitia [16]. According to Blockmans et al., ANCA first involves the retroperitoneal muscular arteries, which later involves aorta [14]. Vaglio et al. found fibrinoid necrosis in vasa vasorum of aorta along with small and medium retroperitoneal vessel involvement and, among 12 of his patients, three were ANCA positive [32].

From the studies analyzed above, we conclude that it is still not clear how aorta is involved in ANCAassociated vasculitis, and further clinical research should be done to find the pathophysiology of this potentially fatal manifestation of ANCA-associated vasculitis.

\section{Possibility of overlap between large-vessel vasculitis and ANCA vasculitis}

Large-vessel vasculitis is divided into GCA and TAK [4]. Antineutrophil cytoplasmic antibodies are not increased in large-vessel vasculitis [33-34]. However, there is a possibility of an overlap between largevessel and small-vessel vasculitis [17,35-36]. Sieber et al. reported a case with an overlap of GCA and GPA in which adventitia and media of aortic walls are involved in the granulomatous process with focal destruction of medial elastic lamellae [17]. The pattern of initial involvement can help to identify ANCA-associated large vasculitis as a different entity than an overlap between large-vessel vasculitis and AAV [12]. Adventitia and media are involved first in large-vessel vasculitis without an ANCA association [12], while intima is involved before media and adventitia in ANCA-associated large-vessel vasculitis [16]. Moreover, ANCA-associated vasculitis predominantly causes perivasculitis, which is not typical of a large-vessel vasculitis [37]. Blockmans et al. described a patient with abdominal periaortitis where inflammatory tissue surrounding aorta had granulomatous vasculitis, a typical feature of granulomatosis with polyangiitis [14]. Carels et al. described a case of a 63-year-old man with aortic aneurysm, who was found to have multiple areas of necrosis in the tissue surrounding the aortic wall, which is a characteristic finding in GPA [13]. Ohta et al. also found necrotizing granulomatous inflammation in aortic walls of a 38-year-old man with granulomatosis with polyangiitis [38]. Pan et al., in a case of a 28-year-old man with GPA, found visible necrosis along with granulation tissue hyperplasia in the aortic wall [18].

Keeping in view the above-described studies, there is very little evidence of an overlap between small- and large-vessel vasculitis. We believe that aortitis in ANCA-positive patients is caused by antineutrophil cytoplasmic antibodies, rather an overlap between the Takayasu arteritis and AAV.

\section{Diagnosis of AAV-related aortitis}

While managing a case of aortitis due to ANCA-associated vasculitis, it is important to keep other differential diagnoses of aortitis in mind, including both infectious and non-infectious causes [4]. Noninfectious causes include other auto-immune diseases, including sarcoidosis, ankylosing spondylitis, Behcet's disease, Sjogren's syndrome, while infectious diseases involving aorta include syphilis and septicemia or endocarditis leading to mycotic aneurysm [4]. The possibility of atherosclerosis should also be ruled out while treating a patient who has developed aortitis [4].

Diagnostic criteria to distinguish granulomatosis with polyangiitis from other forms of vasculitis include nasal or oral inflammation; abnormal chest X-ray showing infiltrates, nodules, or cavities; urinary sediments that include either RBC casts or more than five RBCs per high-power field; and granulomatous inflammation on biopsy [6]. Two of these four criteria should be met for diagnosing GPA [6]. Antineutrophil cytoplasmic antibodies are detected by enzyme-linked immunosorbent assay (ELISA) and indirect immunofluorescence [25]. Immunofluorescence assays are more sensitive, while ELISA is more specific and detects antibodies against specific antigens [39]. Histopathological staining is sufficient for diagnosis of AAV, but special stains and cultures should be obtained to rule out possible infectious causes [6,38]. To detect the involvement of large vessels, non-invasive techniques are used, which include a high-resolution contrast-enhanced MRI combined with magnetic resonance angiography (MRA), contrast-enhanced CT along with computed tomography angiography (CTA), color Doppler sonography, positron emission tomography (PET) with Ffluorodeoxyglucose (FDG), and digital subtraction angiography (DSA) [1]. Carels et al. used an indiumlabeled leukocyte scan to detect the periaortitis and confirmed it with a CT scan [13]. Ohta et al. initially did a chest X-ray when the GPA-positive patient complained of chest pain, which showed a lateral shift of the left lung, suggesting an aortic aneurysm [38]. It was then confirmed with a chest CT scan [38].

It is very important to rule out the large-vessel vasculitis as soon as a diagnosis of AAV is made, and the physician should have a low threshold for chest CTs when a patient with ANCA-associated vasculitis complains of chest pain, as a failure to do so could lead to serious, life-threatening complications [38]. It is also important to distinguish GPA, as a cause of aortitis, from other forms of vasculitis as cyclophosphamide is needed to treat GPA [6].

\section{Treatment of AAV-related aortic involvement}

Treatment of AAV includes induction with corticosteroids or cyclophosphamide, after which maintenance is 
achieved with rituximab or azathioprine $[1,40]$. Corticosteroids only reduce morbidity and mortality in large-vessel vasculitis, but they do not cure the disease nor prevent the relapses [1]. Takenaka et al. used tocilizumab to treat ANCA-associated aortitis when the patient did not respond to corticosteroids or cyclophosphamide [41]. Pineda et al. also used a combination of methotrexate, corticosteroids, and rituximab infusion to successfully treat GPA-associated aortic inflammation [42]. Surgery is needed when a patient develops serious complications, such as an aortic aneurysm or dissection [38].

As summarized in Table 1, ANCA-related aortitis is a very treatable disease, and if timely diagnosed and managed, the patient can recover uneventfully [38]. Prognosis of ANCA-associated aortitis is the same as for ANCA-associated small-vessel vasculitis [16].

\begin{tabular}{|c|c|c|c|c|c|c|}
\hline ID & $\begin{array}{l}\text { Age } \\
\text { (years) } \\
\text { /sex }\end{array}$ & Presentation & $\begin{array}{l}\text { Possible risk } \\
\text { factors/associated } \\
\text { features }\end{array}$ & $\begin{array}{l}\text { Aortic } \\
\text { involvement }\end{array}$ & Treatment & Prognosis/outcome \\
\hline $\begin{array}{l}\text { Case } \\
1 \\
{[14]}\end{array}$ & 42/M & $\begin{array}{l}\text { Fatigue, night sweats, chills, weight } \\
\text { loss, abdominal pain }\end{array}$ & $\begin{array}{l}\text { Ankylosing } \\
\text { spondylitis }\end{array}$ & $\begin{array}{l}\text { Periaortitis and } \\
\text { aortic } \\
\text { dissection }\end{array}$ & $\begin{array}{l}\text { Emergency surgery, } \\
\text { steroids, } \\
\text { cyclophosphamide }\end{array}$ & Slow recovery \\
\hline $\begin{array}{l}\text { Case } \\
2 \\
{[16]}\end{array}$ & 63/M & $\begin{array}{l}\text { Weight loss, peripheral edema, } \\
\text { cutaneous ulcers, fever }\end{array}$ & None found & $\begin{array}{l}\text { Inflammation of } \\
\text { aortic intima }\end{array}$ & $\begin{array}{l}\text { Conservative treatment, } \\
\text { antibiotics }\end{array}$ & Death \\
\hline $\begin{array}{l}\text { Case } \\
3 \\
{[13]}\end{array}$ & 63/M & $\begin{array}{l}\text { Fatigue, fever, back pain radiating to } \\
\text { legs. GPA was diagnosed seven } \\
\text { years later. }\end{array}$ & Idiopathic & $\begin{array}{l}\text { Aortic } \\
\text { aneurysm }\end{array}$ & MDP, surgery & $\begin{array}{l}\text { Good/p-ANCA titers } \\
\text { disappeared }\end{array}$ \\
\hline $\begin{array}{l}\text { Case } \\
4 \\
{[43]}\end{array}$ & 51/M & Lower back pain, weight loss & $\begin{array}{l}\text { HTN, smoking, } \\
\text { chemotherapy }\end{array}$ & $\begin{array}{l}\text { Aortic } \\
\text { aneurysm }\end{array}$ & $\begin{array}{l}\text { MDP, } \\
\text { cyclophosphamide }\end{array}$ & $\begin{array}{l}\text { Anti-PR3 titers } \\
\text { dropped }\end{array}$ \\
\hline $\begin{array}{l}\text { Case } \\
5 \\
{[38]}\end{array}$ & 38/M & $\begin{array}{l}\text { Chest pain, } 22 \text { years after GPA } \\
\text { diagnosis }\end{array}$ & None found & $\begin{array}{l}\text { Aortic } \\
\text { aneurysm, } \\
\text { rupture }\end{array}$ & $\begin{array}{l}\text { Emergency surgery, } \\
\text { prednisolone }\end{array}$ & Uneventful recovery \\
\hline $\begin{array}{l}\text { Case } \\
6 \\
{[41]}\end{array}$ & $47 / F$ & $\begin{array}{l}\text { Lower back and hip pain after GPA } \\
\text { diagnosis }\end{array}$ & None mentioned & Aortitis & $\begin{array}{l}\text { Prednisolone, } \\
\text { cyclophosphamide, } \\
\text { tocilizumab }\end{array}$ & Uneventful recovery \\
\hline $\begin{array}{l}\text { Case } \\
7 \\
{[23]}\end{array}$ & 70/M & $\begin{array}{l}\text { Sudden severe back pain } 18 \text { months } \\
\text { after MPA diagnosis }\end{array}$ & $\begin{array}{l}\text { Non-smoker, AAT } \\
\text { deficiency, GCA }\end{array}$ & $\begin{array}{l}\text { Aortic } \\
\text { dissection }\end{array}$ & MDP, surgery & Death \\
\hline $\begin{array}{l}\text { Case } \\
8 \\
{[18]}\end{array}$ & 28/M & Fatigue, chest pain & None found & $\begin{array}{l}\text { Aortic } \\
\text { dissection }\end{array}$ & $\begin{array}{l}\text { Surgery, MDP, } \\
\text { cyclophosphamide }\end{array}$ & Uneventful recovery \\
\hline
\end{tabular}

\section{TABLE 1: Presentation of aortic diseases in ANCA-associated vasculitis}

Acronyms: male (M); female (F); hypertension (HTN); methylprednisolone (MDP); family history (F/H); chronic obstructive pulmonary disease (COPD); alpha-1 antitrypsin (AAT).

\section{Conclusions}

The main purpose of this paper is to emphasize the possibility of aortic involvement in AAV. Aortic involvement in ANCA-associated vasculitis can range from aortitis to aortic aneurysm and rupture. ANCAassociated aortitis is reported in both granulomatosis with polyangiitis and microscopic polyangiitis but not in Churg-Strauss syndrome. Immunosuppression appears to be the possible risk factor. However, there is a lack of data providing any strong association between the possible risk factors and ANCA-associated aortitis. Diagnosis is made clinically and is confirmed with a biopsy. There is a need for broader research to find the mechanism behind ANCA-associated aortitis, as this will help future clinicians in the timely diagnosis and treatment of this serious manifestation of ANCA-associated vasculitis.

\section{Additional Information}

Disclosures 
Conflicts of interest: In compliance with the ICMJE uniform disclosure form, all authors declare the following: Payment/services info: All authors have declared that no financial support was received from any organization for the submitted work. Financial relationships: All authors have declared that they have no financial relationships at present or within the previous three years with any organizations that might have an interest in the submitted work. Other relationships: All authors have declared that there are no other relationships or activities that could appear to have influenced the submitted work.

\section{References}

1. Younger DS: Overview of the vasculitides. Neurol Clin. 2019, 37:171-200. 10.1016/j.ncl.2019.01.005

2. Jennette JC: Overview of the 2012 revised International Chapel Hill Consensus Conference nomenclature of vasculitides. Clin Exp Nephrol. 2013, 17:603-606. 10.1007/s10157-013-0869-6

3. Jennette JC, Falk RJ, Bacon PA, et al.: 2012 revised International Chapel Hill Consensus Conference nomenclature of vasculitides. Arthritis Rheum. 2013, 65:1-11. 10.1002/art.37715

4. Keser G, Aksu K: Diagnosis and differential diagnosis of large-vessel vasculitides . Rheumatol Int. 2019, 39:169-185. 10.1007/s00296-018-4157-3

5. Jennette JC, Falk RJ, Andrassy K, et al.: Nomenclature of systemic vasculitides. Proposal of an International Consensus Conference. Arthritis Rheum. 1994, 37:187-192. 10.1002/art.1780370206

6. Leavitt RY, Fauci AS, Bloch DA, et al.: The American College of Rheumatology 1990 criteria for the classification of Wegener's granulomatosis. Arthritis Rheum. 1990, 33:1101-1107. 10.1002/art.1780330807

7. Comarmond C, Cacoub P: Granulomatosis with polyangiitis (Wegener): clinical aspects and treatment . Autoimmun Rev. 2014, 13:1121-1125. 10.1016/j.autrev.2014.08.017

8. Karras A: Microscopic polyangiitis: new insights into pathogenesis, clinical features and therapy . Semin Respir Crit Care Med. 2018, 39:459-464. 10.1055/s-0038-1673387

9. de Lind van Wijngaarden RAF, van Rijn L, Hagen EC, et al.: Hypotheses on the etiology of antineutrophil cytoplasmic autoantibody associated vasculitis: the cause is hidden, but the result is known. Clin J Am Soc Nephrol. 2008, 3:237-252. 10.2215/CJN.03550807

10. Pendergraft WF, Niles JL: Trojan horses: drug culprits associated with antineutrophil cytoplasmic autoantibody (ANCA) vasculitis. Curr Opin Rheumatol. 2014, 26:42-49. 10.1097/BOR.0000000000000014

11. Elzouki AN, Segelmark M, Wieslander J, Eriksson S: Strong link between the alpha 1-antitrypsin PiZ allele and Wegener's granulomatosis. J Intern Med. 1994, 236:543-548. 10.1111/j.1365-2796.1994.tb00842.x

12. Chirinos JA, Tamariz LJ, Lopes G, et al.: Large vessel involvement in ANCA-associated vasculitides: report of a case and review of the literature. Clin Rheumatol. 2004, 23:152-159. 10.1007/s10067-003-0816-0

13. Carels T, Verbeken E, Blockmans D: p-ANCA-associated periaortitis with histological proof of Wegener's granulomatosis: case report. Clin Rheumatol. 2005, 24:83-86. 10.1007/s10067-004-0998-0

14. Blockmans D, Baeyens H, Van Loon R, et al.: Periaortitis and aortic dissection due to Wegener's granulomatosis. Clin Rheumatol. 2000, 19:161-164. 10.1007/s100670050038

15. Wiatr E, Dobkowski P, Opoka L, et al.: Wegener's granulomatosis overlapped with Takayasu arteritis complicated by thrombosis of the internal jugular vein [article in Polish]. Pneumonol Alergol Pol. 2003, 71:440-448.

16. Schildhaus HU, Von Netzer B, Dombrowski F, Pfeifer U: Atypical manifestation of a cytoplasmic antineutrophil cytoplasmic antibody (PR3-ANCA)-associated vasculitis with involvement of aortic intima and parietal endocardium. Hum Pathol. 2002, 33:441-445. 10.1053/hupa.2002.124331

17. Sieber SC, Cuello B, Gelfman NA, Garfinkel HB: Pulmonary capillaritis and glomerulonephritis in an antineutrophil cytoplasmic antibody-positive patient with prior granulomatous aortitis. Arch Pathol Lab Med. 1990, 114:1223-1226.

18. Pan L, Yan JH, Gao FQ, et al.: Case report of a 28-year-old man with aortic dissection and pulmonary shadow due to granulomatosis with polyangiitis. BMC Pulm Med. 2019, 19:122. 10.1186/s12890-019-0884-9

19. Vella S, Ramelli GP, Schroth G, Bianchetti MG: Circulating antineutrophil autoantibodies in a child with isolated central nervous system vasculitis. Neuropediatrics. 1999, 30:268-269. 10.1055/s-2007-973502

20. Sakemi T, Tomiyoshi Y, Yano H, Ikeda Y, Matsuo Y, Kudo S: Retroperitoneal fibrosis with perinuclear antineutrophil cytoplasmic antibodies and a longitudinally extended periaortic soft-tissue structure on CT. Nephron. 1998, 78:218-220. 10.1159/000044915

21. Murakami S, Saito H, Ohe M, Kondo T, Oshita F, Yamada K: Periaortitis associated with anti-neutrophil cytoplasmic antibodies induced by bevacizumab combination therapy. Intern Med. 2013, 52:589-591. 10.2169/internalmedicine.52.6632

22. Ginsberg S, Rosner I, Slobodin G, et al.: Etanercept treatment-related c-ANCA-associated large vessel vasculitis. Clin Rheumatol. 2016, 35:271-273. 10.1007/s10067-015-3134-4

23. Voorzaat BM, van Schaik J, Crobach SLP, van Rijswijk CSP, Rotmans JI: Alpha-1 antitrypsin deficiency presenting with MPO-ANCA associated vasculitis and aortic dissection. Case Rep Med. 2017, 2017:8140641. $10.1155 / 2017 / 8140641$

24. Savige J, Pollock W, Trevisin M: What do antineutrophil cytoplasmic antibodies (ANCA) tell us? . Best Pract Res Clin Rheumatol. 2005, 19:263-276. 10.1016/j.berh.2004.10.003

25. Vizjak A, Nagode B, Rott T, et al.: Antineutrophil cytoplasmic autoantibodies-antigen specificity and associated diseases. Wien Klin Wochenschr. 2000, 112:665-670.

26. Johnson RJ: The mystery of the antineutrophil cytoplasmic antibodies . Am J Kidney Dis. 1995, 26:57-61. 10.1016/0272-6386(95)90154-X

27. Pendergraft WF, Pressler BM, Jennette JC, Falk RJ, Preston GA: Autoantigen complementarity: a new theory implicating complementary proteins as initiators of autoimmune disease. J Mol Med. 2005, 83:12-25. 10.1007/s00109-004-0615-3

28. Lúdvíksson BR, Sneller MC, Chua KS, et al.: Active Wegener's granulomatosis is associated with HLA-DR+ CD4+ T cells exhibiting an unbalanced Th1-type T cell cytokine pattern: reversal with IL-10. J Immunol. 1998, 160:3602-3609.

29. Mayet WJ, Meyer zum Büschenfelde KH: Antibodies to proteinase 3 increase adhesion of neutrophils to 
human endothelial cells. Clin Exp Immunol. 1993, 94:440-446. 10.1111/j.1365-2249.1993.tb08215.x

30. Cupps TR, Edgar LC, Fauci AS: Suppression of human B lymphocyte function by cyclophosphamide . J Immunol. 1982, 128:2453-2457.

31. Rarok AA, Stegeman CA, Limburg PC, Kallenberg CGM: Neutrophil membrane expression of proteinase 3 (PR3) is related to relapse in PR3-ANCA-associated vasculitis. J Am Soc Nephrol. 2002, 13:2232-2238. 10.1097/01.asn.0000028642.26222.00

32. Vaglio A, Corradi D, Manenti L, Ferretti S, Garini G, Buzio C: Evidence of autoimmunity in chronic periaortitis: a prospective study. Am J Med. 2003, 114:454-462. 10.1016/s0002-9343(03)00056-1

33. García-Torres R, Noël LH, Reyes PA, et al.: Absence of ANCA in Mexican patients with Takayasu's arteritis . Scand J Rheumatol. 1997, 26:55-57. 10.3109/03009749709065665

34. Ozbakir F, Ugurlu S, Celik AF, Seyahi E: Anti-Saccharomyces cerevisiae (ASCA) and anti-neutrophil cytoplasmic (ANCA) antibodies are not increased in Takayasu arteritis. Acta Reumatol Port. 2011, 36:20-23.

35. Esteban MJ, Font C, Hernández-Rodríguez J, et al.: Small-vessel vasculitis surrounding a spared temporal artery: clinical and pathological findings in a series of twenty-eight patients. Arthritis Rheum. 2001, 44:61387. 10.1002/1529-0131(200106)44:6<1387::AID-ART232>3.0.CO;2-B

36. Hamidou MA, Moreau A, Toquet C, et al.: Temporal arteritis associated with systemic necrotizing vasculitis . J Rheumatol. 2003, 30:2165-2169.

37. Johnston SL, Lock RJ, Gompels MM: Takayasu arteritis: a review . J Clin Pathol. 2002, 55:481-486.

38. Ohta N, Waki T, Fukase S, et al.: Aortic aneurysm rupture as a rare complication of granulomatosis with polyangiitis: a case report. J Med Case Rep. 2013, 7:202. 10.1186/1752-1947-7-202

39. Hagen EC, Andrassy K, Csernok E, et al.: Development and standardization of solid phase assays for the detection of anti-neutrophil cytoplasmic antibodies (ANCA). A report on the second phase of an international cooperative study on the standardization of ANCA assays. J Immunol Methods. 1996, 196:115. 10.1016/0022-1759(96)00111-1

40. Miloslavsky EM, Specks U, Merkel PA, et al.: Clinical outcomes of remission induction therapy for severe antineutrophil cytoplasmic antibody-associated vasculitis. Arthritis Rheum. 2013, 65:2441-2449. 10.1002/art.38044

41. Takenaka K, Ohba T, Suhara K, et al.: Successful treatment of refractory aortitis in antineutrophil cytoplasmic antibody-associated vasculitis using tocilizumab. Clin Rheumatol. 2014, 33:287-289. 10.1007/s10067-013-2457-2

42. Pineda Bernal L, Bitencourt N, Batra K, Solow EB: Successful use of rituximab in granulomatosis with polyangiitis with aortic inflammation. Clin Exp Rheumatol. 2019, 37:144-147.

43. Minnee RC, van den Berk GEL, Groeneveld JO, et al.: Aortic aneurysm and orchitis due to Wegener's granulomatosis. Ann Vasc Surg. 2009, 23:786-15. 10.1016/j.avsg.2009.06.011 